\title{
Co-pyrolysis characteristics and kinetics of lignin and collagen
}

Zilong Zhao ${ }^{\text {a,b,c,** }}$, Fred. S. Cannon ${ }^{\mathrm{c}}$, and Cesar Nieto-Delgado ${ }^{\mathrm{d}}$

${ }^{a}$ School of Civil and Environmental Engineering, Harbin Institute of Technology Shenzhen

Graduate School, Shenzhen 518055, P.R. China

${ }^{\mathrm{b}}$ Department of Municipal Engineering, Southeast University, Nanjing 210096, P.R. China

${ }^{c}$ Department of Civil and Environmental Engineering, The Pennsylvania State University, 225 Sackett Building, University Park, PA 16802, United States

${ }^{d}$ División de Ciencias Ambientales, Instituto Potosino de Investigación Científicay Tecnológica A.C., Camino a la presa de San José 2055, Col. Lomas 4a sección, San Luis Potosí, SLP 78216, Mexico

\begin{abstract}
The authors have investigated apparent activation energies of volatiles emission when using (a) lignin alone, (b) collagen alone, or (c) lignin-collagen blends as a thermally-strengthened binder for high-density carbon product manufacturing. Apparent activation energies $\left(E_{a}\right)$ computed by the Kissinger, the Weibull, and the Flynn-Wall-Ozawa (FWO) methods showed the same trends: with the highest $E_{a}$ for lignin alone $(245 \mathrm{~kJ} / \mathrm{mol})$, and the lowest for collagen alone $(194 \mathrm{~kJ} / \mathrm{mol})$. The blends pyrolysis exhibited synergistic presence of collagen, which could help initiate the pyrolysis mass loss reactions at $250 \sim 400{ }^{\circ} \mathrm{C}$, and participate in the condensation reactions of aromatic fragments at $400 \sim 800{ }^{\circ} \mathrm{C}$, leading to less emission of some gaseous products and more preservation of residual char. In prior Penn State work, it was observed that this thermallyinduced preservation and condensation of aromatic structure increased the binding strength of the
\end{abstract}

\footnotetext{
${ }^{*}$ Corresponding author.

E-mail addresses: berthillon@hotmail.com
} 
lignin-collagen binders. The work herein offers thermogravimetric concurrence and insight to this thermal-binding synergism.

Keywords: Co-pyrolysis; Lignin; Collagen; TGA-MS; Synergic interaction.

\section{Introduction}

Biomass offers a major alternative energy sources that is environmentally sustainable and fuel efficient. As one of the major components of biomass, lignin is the second most abundant natural compound after only cellulose, thus, lignin attracts considerable interest as a renewable feedstock of aromatic chemicals, biofuels and other value-added products. Among the various thermochemical conversion route of lignin, pyrolysis process has been widely employed for converting lignin directly into bio-oil, char, solid fuel, aromatics, hydrogen and syngas products in the absence of oxygen [1]. Ongoing Penn State research has shown that a combined lignin-collagen binder system offers considerable unconfined compressive strength (UC strength). Specifically, the collagen has provided strength at ambient temperature. The lignin provides strength at elevated pyrolysis temperatures, and the collagen synergistically enhanced the lignin pyrolysisinduced strength [2].

In the research by other groups, it has been mostly assumed that lignin has pyrolytically decomposed in a manner that is independent and parallel to other biomass components; and the pyrolysis process has been generally perceived as a superposition of the independent thermokinetics of each component [3]. However, several others have noted that lignin co-pyrolysis generally involves heterogeneous chemical reactions; and the presence of heterogeneous materials may lead to the variation of the interfacial reactions and the influence of catalytic effects [4]. For example, Worasuwannarak et al. [5] considered that the cross-linking reactions between lignin and cellulose contributed to a decrease in tar yields but an increase in char yields, which were revealed by the formation of $\mathrm{H}_{2} \mathrm{O}$ and ester groups during the pyrolysis. Faix et al. [6] discerned that the guaiacyl units in lignin structure are prone to initiate thermal condensation reactions and coupling reactions under pyrolytic conditions. Sharma et al. [7] attributed the higher char formation to the promotion of dehydration, demethoxylation and recombination of the primary radicals by some naturally occurring inorganic materials in lignin residue, such as sodium and potassium. Other carbonaceous additives in lignin blends have also affected the kinetic parameters and 
volatilization rates during thermogravimetric analysis [8,9]. Also, the hydroxyl groups in lignin can cross-couple with the amino acids in proteins [10].

A Penn State team, in collaboration with Furness-Newburge has been developing a binder system comprised of clean lignin plus collagen plus other additives $[2,11,12]$. This work also builds on Penn State research in characterizing and diminishing volatile organic pollutants [13]. As alternatives to conventional foundry coke, the bindered anthracite briquettes have exhibited promise during full-scale cupola demonstrations to offer faster burning rates, higher combustion efficiency, less energy consumption, and lower life-cycle pollution emission [12]. Another motivation for using biomaterial-based binders is that these can replace petrochemical-based polyaromatic hydrocarbons, which can pose health hazards, and are regulated by European REACH regulations, lignin and collagen are not polyaromatic hydrocarbons, and are not regulated by REACH.

Collagen is comprised of a triple-stranded helical superstructure of extended polypeptide chains, and these provide considerable binding strength at ambient temperature [11]. Also, the synergic interaction among the pyrolysis products of lignin, denatured collagen, and anthracite fines during the heating process, imparted better mechanical performances to these briquettes, as evidenced by the doubling of unconfined compressive strength when the addition of collagen increased from $0.45 \%$ to $1.8 \%$ [2]. Based on these favorable results with bindered anthracite bricks and foundry core binders, the authors herein pursued yet another biomass binder opportunity, we aimed to devise biomaterial-based binders from lignin plus collagen to replace petrochemical pitches and mined pitches for other carbon product manufacturing.

An important factor relative to these biomaterials binders is to better understand their pyrolysis thermal decomposition, and this can be characterized by therogravimetric analysis-mass spectrophotometry(TGA-MS). The thermal decomposition of lignin and collagen proceeds by a series of reactions that yield various gaseous products at progressively higher pyrolysis temperatures. Britt et al. proposed that lignin pyrolysis principally followed free-radical reaction mechanism [4]. Fenner and Lephardt [14] reported the pyrolytic decomposition of Kraft pine lignin could be described as a three-stage process: (a) single bond fragmentation occurred in the phenyl propane side chains between 120 and $300{ }^{\circ} \mathrm{C}$, (b) cleavage and fragmentation of principal chain linkages between the monomeric phenol units occurred in the $300 \sim 480{ }^{\circ} \mathrm{C}$ temperature range and (c) the 
onset of secondary degradation, occurred yet at higher temperatures. The most apparent gaseous species released at $120 \sim 480{ }^{\circ} \mathrm{C}$ (i.e. the first two stages) included formic acid, formaldehyde, water, carbon dioxide, carbon monoxide, methanol, methane, and some phenolic compounds. In comparison, collagen pyrolysis is primarily characterized by the thermal effects on the amino acids. Sharma et al. [15] noted that significant decomposition of amino acids generally occurred at $300{ }^{\circ} \mathrm{C}$, then at higher temperatures, the amino acids experienced dehydration, decarboxylation, and deamination reactions, and these yielded low molecular weight heterocycles and gaseous products as a common pool of building blocks. Then at yet higher temperatures, these subsequently pyrosynthesized into larger heterocyclic and polycyclic aromatic hydrocarbons that were comprised of 5 to 7 rings [16]. Haidar et al. [17] believed that the species composition of the amino acid has a significant effect on its transformation percent to gaseous products: the smaller the amino acid and the less encumbered it was with extra functional groups, the more thoroughly it is converted to gases. At $850{ }^{\circ} \mathrm{C}$ in a helium atmosphere, small and simple amino acids generally yield a high proportion of gaseous products, including $\mathrm{CO}_{2}, \mathrm{CO}, \mathrm{HCN}, \mathrm{NH}_{3}, \mathrm{CH}_{4}, \mathrm{C}_{2} \mathrm{H}_{4}$, $\mathrm{C}_{2} \mathrm{H}_{6}$. In contrast, when pyrolyzed at $850{ }^{\circ} \mathrm{C}$, the high molecular weight complex amino acids can yield relatively stable nitrogen-containing aromatic rings.

The differences in reactivity between lignin and collagen could be expected to render the copyrolysis processes rather complex, and these thermal reactions could be influenced by multiple factors, such as temperature, feedstock composition, and catalysts. In the present work, the pyrolysis behaviors and gaseous products of lignin, collagen and their blends were further investigated by means of thermogravimetric analysis-mass spectrometry. The synergy interactions between lignin and collagen during co-pyrolysis were identified by comparing the corresponding pyrolysis characteristics, such as: char yields, mass loss fraction, gaseous product distributions and thermal decomposition kinetics parameters.

\section{Experimental and modeling}

\subsection{Materials}

Pine softwood lignin, which had been extracted from Kraft black liquor, was provided by Innventia (Stockholm, Sweden). Softwood lignin has been characterized as an aromatic alcohol having a moderate molecular weight structure that in comparised of guaiacyl-type units, i.e. singlet 
aromatic rings linked to a methoxyl (-OCH 3$)$, hydroxyl $(-\mathrm{OH})$, and alkyl chain ($\mathrm{CH}=\mathrm{CHCH}_{2} \mathrm{CH}_{2} \mathrm{OH}$ ). This cleaned softwood lignin contained 1 2\% sulfur. Collagen was obtained as solid particles from Entelechy (Plymouth, MI). Collagen has a triple helical structure, and its primary amino acids generally include: glycine (about 34\%, $\mathrm{NH}_{2} \mathrm{CH}_{2} \mathrm{COOH}$ ); proline (about $12 \%$, ring $\mathrm{C}_{5} \mathrm{H}_{9} \mathrm{NO}_{2}$ ); alanine (about $10 \%, \mathrm{CH}_{3} \mathrm{CHNH}_{2} \mathrm{COOH}$ ); hydroxyproline (about $10 \%$, ring $\mathrm{C}_{5} \mathrm{H}_{9} \mathrm{NO}_{3}$ ); glutamic acid (about 7\%, alkyl $\mathrm{COOHCH}_{2} \mathrm{CH}_{2} \mathrm{CHNH}_{2} \mathrm{COOH}$ ), and other amino acids $[11,18]$.The blends of lignin and collagen were prepared by dissolution of collagen into $20 \mathrm{~g}$ water at $70^{\circ} \mathrm{C}$ and the subsequent addition of lignin, which were labelled according to the mass ratio of lignin to collagen as follows: L5-C1, L7-C1, L9-C1. Both the lignin and the blends were ground to a size range less than a US \# 100 mesh $(152 \mu \mathrm{m})$ and dried at $60{ }^{\circ} \mathrm{C}$ for a week before each experiment.

\subsection{Pyrolysis process}

Dynamic pyrolysis processes were performed by a thermogravimetric analyzer (TA instruments TGA 2050). All the samples for the measurements were used in powder form in order to minimize heat and mass transfer effects during measurements. Experimental runs were carried out at temperatures in the range of room temperature to $800{ }^{\circ} \mathrm{C}$, using a range of nominal heating rates: $10,30,60$, or $100{ }^{\circ} \mathrm{C} / \mathrm{min}$. For each run, approximately $20 \mathrm{mg}$ samples were transferred onto a platinum pan, while nitrogen gas $\left(\mathrm{N}_{2}\right)$ flowed at $100 \mathrm{~mL} / \mathrm{min}$ was used as a non-reactive atmosphere that conveyed all the gaseous intermediate products. Considering the retarding effect of moisture content on the pyrolysis rate, all the samples were preheated to $100{ }^{\circ} \mathrm{C}$ at selected heating rate of $5{ }^{\circ} \mathrm{C} / \mathrm{min}$ and held for $10 \mathrm{~min}$ before pyrolysis. Replicate runs 2,3 or 5 were carried out for each blend and pyrolytic conditions, in order to ensure reproducible data, and the mass results presented herein represent the averaged of these replicates. Also, the statistical significance between the various blends and ramp-rates were appraised by the least significant difference (LSD) test [19]. Except as specifically identified, the final $\left(800^{\circ} \mathrm{C}\right)$ mass loss values and mass loss at $375^{\circ} \mathrm{C}$ were truly different between blends and ramping rates to the $95 \%$ confidence interval. The exception was when comparing lignin to $\mathrm{L} 9-\mathrm{C} 1$ at $800^{\circ} \mathrm{C}$ following at $10{ }^{\circ} \mathrm{C} / \mathrm{min}$ ramping, when where was a true difference at the $90 \%$ confidence interval. 


\subsection{Thermogravimetric analysis-mass spectrometry}

The gaseous products responsible for the mass loss during the pyrolysis processes was monitored with a thermogravimetric analyzer (TA instruments TA Q50) coupled to a Pfeiffer Vacuum mass spectrometer in Trend Run mode. Before starting the Trend Run analysis, a preliminary bargraph scan was performed at a heating rate of $10^{\circ} \mathrm{C} / \mathrm{min}$ so as to record the main mass spectra between 10 and $200 \mathrm{amu}$. The protocol for the TGA-MS was similar as for the TGA (alone); except that the TGA-MS runs used argon as the carrier gas $(100 \mathrm{~mL} / \mathrm{min})$. Duplicate TGA-MS runs were conducted for each lignin and/or collagen blend, and the results reported here in are the average of the two runs.

\subsection{Pyrolysis kinetics theory and apparent activation energy modeling}

In general, the pyrolysis kinetic of solid-state reactions under non-isothermal conditions can be expressed through the superficial transformation of the Coats-Redfern formula [20], given as follows:

$$
\frac{\mathrm{d} \alpha}{\mathrm{dt}}=\beta\left(\frac{\mathrm{d} \alpha}{\mathrm{dT}}\right)=\mathrm{A} \exp \left(-\frac{E_{a}}{R T}\right) f(\alpha)
$$

Where $\alpha$ refers the relative pyrolysis mass loss conversion, expressed by $\left(m_{0}-m\right) /\left(m_{0}-\right.$ $\left.m_{800}\right)$. Here $m_{0}$ is the initial mass of sample, $m$ is the actual mass at time $t, m_{800}$ is the residual mass after pyrolysis up to $800{ }^{\circ} \mathrm{C}$, herein. $\mathrm{d} \alpha / \mathrm{dt}$ signifies the reaction rate of the pyrolysis process, $\beta$ represents the linear heating rate, namely $\beta=d T / d t$. A is the pre-exponential factor, $E_{a}$ is the apparent activation energy, $R$ is the ideal gas constant, $T$ is the reaction temperature and $f(\alpha)$ is a conversion function that depends on the reaction model used and controlling mechanism.

Based on Eq. (1), the mathematical methods available for analyzing the kinetic of biomass thermal decomposition in the present study have been as summarized in Table 1. Notably, these three methods do not provide any mechanism details beforehand, but predict the most complicated reaction behavior by describing the kinetics with apparent activation energy as a function of temperature.

The Kissinger method [21] evaluates apparent activation energy by plotting plotting $\ln \left(\beta / \mathrm{T}_{\mathrm{m}}^{2}\right)$ versus $1 / T_{m}$ at different heating rates. Herein, $T_{m}$ is the temperature corresponding to the maxi- 
mum reaction rate obtained from differential thermogravimetry (DTG) curves. Following the Kissinger method, the values of other kinetic parameters, known as reaction order ( $\mathrm{n}$ ), and preexponential factor A, are given by the expression listed in Table 1 [21,22]. Thus, for this method, we first discern the $\mathrm{T}_{\mathrm{m}}$ and $\alpha_{\mathrm{m}}$, where $\alpha_{\mathrm{m}}$ is the conversion rate corresponding to the peak temperature, then from the slopes of $\ln \left(\beta / \mathrm{T}_{\mathrm{m}}^{2}\right)$ versus $1 / \mathrm{T}_{\mathrm{m}}$ plots, we solve for $E_{a}$. For each TGA run, we next compute the reaction order $n$, which is a function of $\alpha_{m}$. Then we compute the preexponential $\mathrm{A}$, which for each TGA run is a function of $\mathrm{T}_{\mathrm{m}}, \alpha_{\mathrm{m}}, E_{a}$, and the heating rate $\beta$.

The Weibull distribution function has been confirmed to simulate the distribution of the apparent activation energy values for various homogeneous processes [23]. By introducing the specific shape parameter $(\theta)$, scale parameter $(\eta)$ and corresponding rate constant $\left(1 / \eta, \min ^{-1}\right)$, the $\mathrm{y}$-axis, $\ln (1 / \eta)$ is plotted versus the $\mathrm{x}$-axis $\left(1 / T_{p}\right)$ for each heating rate, and these plots generate straight lines that have a slope of $-\mathrm{E}_{a} / \mathrm{R}$. The values of Weibull distribution parameters can be determined from equations as presented in Table 1. For this method, we first compute the $\theta$ and $\eta$ from the slopes of $\ln [-\ln (1-\alpha)]$ versus $\ln \left[\left(T-T_{0}\right) / \beta\right]$ plots, then we compute the $T_{p}$,

which is a function of $\theta, \eta$, and $\beta$. Then from the slope of $\ln (1 / \eta)$ versus $\left(1 / T_{p}\right)$, we solve for $E_{a}$. Where $T_{0}$ stands for the starting temperature and acts as the location parameter, and $\mathrm{T}_{\mathrm{p}}$ is as defined in Table 1.

The Flynn-Wall-Ozawa (FWO) integral method assumes the apparent activation energy remains constant throughout the duration of the reaction [24]. Given a fixed degree of conversion, plots of $\log \beta$ versus $1 / \mathrm{T}$ for each heating rate produce a set of straight lines, and the slope $\left(-0.4567 \mathrm{E}_{a} / \mathrm{R}\right)$ of these lines is proportional to the apparent activation energy, that corresponds to that span of conversions.

\section{Results and discussion}

\subsection{Thermal decomposition and synergistic interactions between lignin and collagen}

When the lignin was pyrolyzed to $800{ }^{\circ} \mathrm{C}$, it retained $42 \%$ of its mass, and this compared to $25 \%$ mass retained for the pyrolyzed collagen, as presented in Table 2 (see representation TGA mass loss curves in Supplementary Fig. S1). The blends of lignin plus collagen retained slightly 
higher mass $(43 \%)$ than did mere lignin, and this highlighted the cross-linking reactions that occurred between the lignin and collagen, as discussed below.

From the TGA mass loss curves, the authors computed non-isothermal conversion curves, for which the $\mathrm{x}$-axis was Temperature, and the $\mathrm{y}$-axis was the fractional conversion $\alpha$, where $\alpha=$ $\left(m_{0}-m\right) /\left(m_{0}-m_{800}\right)$. As shown in Fig. la, the collagen reached greater fractional conversion $\alpha$ at lower temperature than did the lignin. Moreover for each material, a given fractional conversion occurred at lower temperature for a slower ramping rate. Per Fig. 1b, the L5-C1 blend exhibited fractional conversion that was closer to that for lignin than for collagen.

In order to investigate the synergistic thermal interactions between lignin and collagen, we defined the difference of mass loss fractions $(\Delta M)$ for their blends between the experimental values $\left(M_{\text {exp }}\right)$ and the calculated values $\left(M_{\text {cal }}\right)$, as follows:

$$
\Delta M=M_{\text {exp }}-M_{c a l}, M_{c a l}=\left(x_{1} M_{1}+x_{2} M_{2}\right)
$$

Where $M_{c a l}$ is the sum of mass loss "fractions" of each pure component, which serves as a baseline for the comparison, i.e. the result that would be expected if there was no synergistic interaction. $x_{i}$ is the mass fraction of each component in the blend, $M_{i}$ is the mass loss fraction of each component at the same temperature during the same ramping temperature conditions.

The variation of $\Delta M$ with temperature for different lignin-collagen blends have been presented in Fig. 2 for the $10{ }^{\circ} \mathrm{C} / \mathrm{min}$ and $60^{\circ} \mathrm{C} / \mathrm{min}$ ramping conditions. For example, at $10^{\circ} \mathrm{C} / \mathrm{min}$, these plots show that at about the temperature of $283 \sim 435^{\circ} \mathrm{C}$, the blends released volatile more rapidly than if there was no synergistic interactions by $0 \sim 2.9 \%$ more. Then in the $435 \sim 800{ }^{\circ} \mathrm{C}$ temperature range, the blends released less mass than if there were no synergistic interactions (by 0 to 2.7\%). These synergistic effects are more prominent for the slower ramping rates than for the faster ramping rates. This indicates that these synergistic reactions could be rather slow. The $283 \sim 435^{\circ} \mathrm{C}$ range corresponds to the temperatures where lignin and collagen substituents are released, as manifest by the release of ammonia, $\mathrm{OH} \cdot$, and formaldehyde, as discussed further below. Then, the $435 \sim 800{ }^{\circ} \mathrm{C}$ range corresponds to where the lignin and collagen can engage in forming 5 7 member aromatic rings [16]. This thermal ring development is important when these biomaterials are used for thermally-strengthened binders [2]. 


\subsection{Kissinger method for computing apparent activation energy}

From the TGA mass loss plots, the authors next computed differential thermogravimetric (DTG) plots, and this has been representatively presented in Fig. 3 for the 5 specimen, at $10{ }^{\circ} \mathrm{C} / \mathrm{min}$ heating rate. It could be discerned that the temperatures $\left(\mathrm{T}_{\mathrm{m}}\right)$ corresponding to maximum reaction rate are also exhibited in Fig. 3. As shown, $\mathrm{T}_{\mathrm{m}}$ was $404{ }^{\circ} \mathrm{C}$ for lignin, $341^{\circ} \mathrm{C}$ for collagen, and $378 \sim 385^{\circ} \mathrm{C}$ for the 3 other blends. These $\mathrm{T}_{\mathrm{m}}$ values have been tabulated in Table 2 , along with the $\mathrm{T}_{\mathrm{m}}$ values for the other heating rates (refer to Fig. S2a-c). For a given blend, $\mathrm{T}_{\mathrm{m}}$ increased with increasing ramping rate.

The fractional conversion $\left(\alpha_{\mathrm{m}}\right)$ that corresponded to $\mathrm{T}_{\mathrm{m}}$ are also presented in Table 2. The $\alpha_{\mathrm{m}}$ values were in the 0.45 to 0.58 fractional conversion range; and they were higher at faster ramping rates. The same phenomenon can be also observed from the maximum peak temperature shift in the corresponding non-isothermal differential $(\mathrm{d} \alpha / \mathrm{dt}-\mathrm{T})$ reaction rate curves (Supplementary Fig. S3a-e).

The apparent activation energies based on Kissinger method computations are presented in Table 2. As shown, the apparent activation energy for collagen alone was $164 \mathrm{~kJ} / \mathrm{mol}$; and for lignin alone was $208 \mathrm{~kJ} / \mathrm{mol}$. For the three lignin-collagen blends, the $E_{a}$ values were $175 \sim 191 \mathrm{~kJ} / \mathrm{mol}$; with increasing apparent activation energy corresponding to increasing lignin proportions. These apparent activation energies emphasize the mass loss rates at the range of temperatures corresponding to maximum mass loss rate namely in $341 \sim 446{ }^{\circ} \mathrm{C}$ range, while $\alpha_{\mathrm{m}}$ is 0.45 to 0.58 (Table 2).

The Kissinger method also facilitated computation of the reaction order $\mathrm{n}$. As shown in Table 2 , the $\mathrm{n}$ ranged from 1.3 to 2.6 for all the specimen and ramping rates. The reaction order was generally higher for slower ramping rates than for high ramping rates. Also, $\mathrm{n}$ was higher for greater proportions of collagen; for mere collagen, $\mathrm{n}$ was 1.8 to 2.6, and for mere lignin, $\mathrm{n}$ was 1.3 to 1.9. Reactions that invade free radicals are often second order $[25,26]$. Thus, the observed trends infer that when collagen is present, it is the free radicals that arise from amino acid pyrolysis that catalyze the volatilization of the lignin in the $\mathrm{T}_{\mathrm{m}}$ and $\alpha_{\mathrm{m}}$ region (i.e. in the $341 \sim 446{ }^{\circ} \mathrm{C}$ range per the Kissinger method). This is discussed below. 


\subsection{Weibull method for computing apparent activation energy}

For the Weibull method, the values of Weibull distribution parameters were determined by the slope and intercept, when plotting $\ln [-\ln (1-\alpha)]$ versus $\ln \left[\left(T-T_{0}\right) / \beta\right]$, as shown in Fig. 4, for the lignin and collagen. These plots for the blends are presented as Fig. S4a-c. These slopes were generally linear for the range of $\ln [-\ln (1-\alpha)]$ that spans from -4.9 to +0.2 , and this corresponded to fractional conversion $\alpha$ of 0.01 to 0.7 . As tabulated in Table 3, the Weibull $E_{a}$ for lignin was $247 \mathrm{~kJ} / \mathrm{mol}$, and for collagen was $194 \mathrm{~kJ} / \mathrm{mol}$. The blends hosted $E_{a}$ values of 233 to $244 \mathrm{~kJ} / \mathrm{mol}$, and increased with increasing lignin fraction. These Weibull $E_{a}$ values were slightly higher than the Kissinger $E_{a}$ values of 164 208 kJ/mol (see Table 4); and this was because the Weibull method included a wider span of fractional conversion $\alpha$ in its computation.

\subsection{Flynn-Wall-Ozawa method for computing apparent activation energy}

For the Flynn-Wall-Ozawa (FWO) method, apparent activation energies are computed from Arrhenius-like plots of $\log \beta$ versus $1 / \mathrm{T}$. These plots are computed for a given degree of conversion $(\alpha)$, where $1 /$ temperature corresponding to that $\alpha$ is plotted against the $\log \beta$ for the four ramping rates (i.e. $\beta=10^{\circ} \mathrm{C} / \mathrm{min}$ up to $\beta=100^{\circ} \mathrm{C} / \mathrm{min}$ ). These Arrhenius-like plots are presented in Fig. S5a-e. From these slopes are computed the apparent activation energies corresponding to the degrees of conversion $(\alpha)$, as presented in Fig. 5. The averages of apparent activation energies are also tabulated in Table 4 over particular ranges of fractional conversion $\alpha$. For example, over the $\alpha$ range of 0.45 to 0.55 , the FWO apparent activation energies averaged $210 \mathrm{~kJ} / \mathrm{mol}$ for collagen, $259 \mathrm{~kJ} / \mathrm{mol}$ for lignin, and $249 \sim 268 \mathrm{~kJ} / \mathrm{mol}$ for the blends (Table 4). It is noted that in this $\alpha=0.45$ to 0.55 range, mass loss rates are the fastest (as discussed for the Kissinger method above).

\subsection{Flynn-Wall-Ozawa apparent activation energies at various temperatures}

When characterizing lignin and its blends, ranged below about $322^{\circ} \mathrm{C}$ corresponding to $\alpha<$ 0.2 , the FWO apparent activation energies ranged between 220 to $266 \mathrm{~kJ} / \mathrm{mol}$. The authors discussed that these mainly accounted for the release of partial light volatiles, such as moisture, carbon dioxide, carbon monoxide, formaldehyde, methanol, methane, etc., as discussed further below, relative to TGA-MS results in section 3.6. A literature survey of the apparent activation energies for $\mathrm{C}-\mathrm{O}$ bonds cleavage from $\alpha$ or $\beta$-alkyl aryl ether linkage in lignin structure exhibit an $E_{a}$ range of (202.1 302.5 kJ/mol) [27], Thus, it was surmised that the first radical initiation reac- 
tion of lignin pyrolysis involved the rupture of thermolabile ester linkages between the monomeric units, and the cracking of the phenyl propane lateral chains. Since the shape of $E_{a}$ dependence up to the conversion in the case of lignin-collagen blends followed the similar trend, it was surmised that the collagen did not affect the degradation reactions of lignin pyrolysis. Nonetheless the collagen definitely enriched the variety of gaseous products in this region (see section 3.6).

The conversion range of $0.2 \leqq \alpha \leqq 0.45$, corresponded to temperatures in the $322 \sim 427{ }^{\circ} \mathrm{C}$ range, where mass loss was the most rapid. For this range of the $\alpha$ and T, the values of FWO apparent activation energy are relatively uniform, with the $\mathrm{E}_{a-\text { Lignin }}=245 \mathrm{~kJ} / \mathrm{mol}, \mathrm{E}_{a-L 9-C 1}=242$ $\mathrm{kJ} / \mathrm{mol}, \mathrm{E}_{a-L 7-C 1}=240 \mathrm{~kJ} / \mathrm{mol}, \mathrm{E}_{a-L 5-C 1}=225 \mathrm{~kJ} / \mathrm{mol}$, and $\mathrm{E}_{a-\text { Collagen }}=194 \mathrm{~kJ} / \mathrm{mol}$. Notably, these $\mathrm{E}_{a}$ values are nearly identical to the Weiball $\mathrm{E}_{a}$ values (see Table 4). For lignin pyrolysis, the $\mathrm{E}_{a}$ values in these $\alpha$ and $\mathrm{T}$ range could be attributed to the demethoxylation of the aromatic rings, which per TGA-MS yielded methanol, methane and other radical fragments of these gases (see section 3.6). These apparent activation energies were very close to the value of $\mathrm{E}_{a}=251.2$ $\mathrm{kJ} / \mathrm{mol}$, which is published in the literature for such demethoxylation reactions [28]. Also, in this temperature range, the amine groups in the collagen could be released as ammonia and radical fragments of ammonia, as described below. Within this temperature and $\alpha$ range, radical propagation reactions that are related to constant values of apparent activation energy occur rather readily at well-defined sites to form intermediate radicals and oxygen-bridge bonds, as well as volatile species. Meanwhile, greater proportions of collagen corresponded to decreasing apparent activation energy and also accelerated mass loss in this temperature (Fig. 2); and these trends indicated that the collagen facilitated the initiation of this devolatilization, by apparently weakening the links sites.

With further temperature rise above $427^{\circ} \mathrm{C}$, the limiting degradation step of lignin and blended lignin-collagen degradation shifted toward to a complex set of radical competitive and concurrent reactions. Then at temperatures above $452^{\circ} \mathrm{C}$, with $\alpha>0.6$, the FWO plots exhibited increasing $\mathrm{E}_{a}$ to about $324 \mathrm{~kJ} / \mathrm{mol}$ at $\alpha=0.65$; then yet further up to $421 \mathrm{~kJ} / \mathrm{mol}$ above $\alpha=0.7$. Avni and Coughlin [29] attributed such conversion-dependent apparent activation energy change to the variation of aromatic condensation degree. It can be pointed out that, $\mathrm{C}-\mathrm{C}$ bonds cleavage from $\beta-\mathrm{O}-4$ linkage in lignin structure exhibited the apparent activation energy of $301.4 \mathrm{~kJ} / \mathrm{mol}$ or 
more, the bond dissociation energies for the $\mathrm{OCH}_{3}-\mathrm{Ph}$ and $\mathrm{HO}-\mathrm{Ph}$ were $418.6 \mathrm{~kJ} / \mathrm{mol}, 468.8$ $\mathrm{kJ} / \mathrm{mol}$, repectively $[27,28]$. Thus, intermolecular and intramolecular aromatic condensation reactions were surmised as the major processes in this temperature and $\alpha$ region, leading to the continuous cross-linking and growth of the aromatic rings. In contrast to the slope of fitting dependence curves for lignin and collagen in this conversion range, remarkable enlargement of the slope for lignin-collagen blends took place by introducing collagen into lignin, indicating that the collagen improved the fused ring networking by supplying some aryl carbon sources during the copyrolysis of lignin and collagen. This fusing, in turn, corresponded to diminished mass loss. Indeed, per Fig. 2, the collagen plus lignin engaged in a synergistic effect that enhanced this ring fusing mechanism, and thus diminished the mass loss rate.

\subsection{Thermogravimetric analysis-mass spectrophotometry gas products analysis}

The authors employed thermogravimetric analysis-mass spectrophotometry (TGA-MS) to characterize product gases of several molecular weights. The TGA-MS appraised lignin, collagen, and the three blends while temperature was ramped at $10^{\circ} \mathrm{C} / \mathrm{min}$ under argon gas. MS monitored gases that had $\mathrm{m} / \mathrm{z}$ molecular weights of $14\left(\mathrm{CH}_{2}:\right), 15\left(\mathrm{CH}_{3} \cdot\right), 16\left(\mathrm{CH}_{4}\right), 17\left(\mathrm{NH}_{3}\right.$ or $\left.\mathrm{OH} \cdot\right)$, $18\left(\mathrm{H}_{2} \mathrm{O}\right), 28\left(\mathrm{CO}\right.$ or $\left.\mathrm{N}_{2}\right), 30\left(\mathrm{OCH}_{2}\right.$ or $\left.\mathrm{NO}\right), 32\left(\mathrm{CH}_{3} \mathrm{OH}\right.$ or $\left.\mathrm{O}_{2}\right)$, and $44\left(\mathrm{CO}_{2}\right)$. This TGA-MS protocol can discern molecular weights, but it cannot distinguish between species that host the same molecular weight. For example this TGA-MS cannot distinguish between formaldehyde $\left(\mathrm{OCH}_{2}\right)$ and $\mathrm{NO}$, which both host a molecular weight of 30. Representative ion current spectra for $\mathrm{m} / \mathrm{z} 17$ and 30 have been presented in Fig. 6a-b, which the other spectra are chronicled in Supplementary Fig. S6.

The lignin contains $\mathrm{C}, \mathrm{O}$, and $\mathrm{H}$, but no $\mathrm{N}$. Thus, for lignin (alone) m/z 17 can only be $\mathrm{OH}$, and $\mathrm{m} / \mathrm{z} 30$ can only be $\mathrm{OCH}_{2}$. Collagen, however, includes nitrogen in amino acids that include an amine group (as in glycine, alanine, and glutamic acid), and upon pyrolysis, these could be released as ammonia $\left(\mathrm{NH}_{3}, \mathrm{~m} / \mathrm{z}=17\right)$. Thus, in Fig. $6 \mathrm{a}$, the considerably higher released by collagen of $\mathrm{m} / \mathrm{z} 17$ in the $250 \sim 450{ }^{\circ} \mathrm{C}$ range could be attributed at least in part to amine decomposition. Also collagen includes nitrogen in 5-sided rings (as in proline, and hydroxyproline). Upon pyrolysis, these could be released as $\mathrm{H}_{2} \mathrm{NCH}_{2}$ or NO. Thus in Fig. 6b, the considerably higher release by collagen of $\mathrm{m} / \mathrm{z} 30$ in the $400 \sim 800{ }^{\circ} \mathrm{C}$ range could be attributed (at least in part) to ni- 
trogen-containing ring decomposition. It is notable that the amines started decomposing at lower temperatures than did the nitrogen-containing rings as could be expected.

The authors have also tabulated the TGA-MS ion currents generated for all these $\mathrm{m} / \mathrm{z}$ values, as presented in Table 5. These have been tabulated within several characteristic temperature ranges for the lignin, collagen, and L5-C1. Moreover, the experimentally-mixed L5-C1 blend has been compared to the mathematically-normalized addition of lignin plus collagen (per an equation similar to equation 2). This normalized addition would be as expected if there were no synergistic interactions between collagen and lignin. However, as shown per Table 5, such synergistic interaction did indeed occur, as manifested by less of these low molecular weight gases being released when lignin and collagen were physically mixed together. There were only a few exceptions to this, such as $\mathrm{H}_{2} \mathrm{O}$ emission in the temperature range of $250 \sim 400{ }^{\circ} \mathrm{C}$, and $\mathrm{CO}_{2}$ released at $250 \sim 283{ }^{\circ} \mathrm{C}$.

When comparing Fig. 2 to Table 5, one observes that synergistic binding effects between collagen and lignin diminished both mass loss and release of most of these low molecular weight gases $(\mathrm{m} / \mathrm{z} 14 \sim 44)$, during pyrolysis at $435 \sim 800{ }^{\circ} \mathrm{C}$. This is a favorable effect, from the perspective of devising binders that withstand pyrolysis decomposition. Similar to a synergistic increase in TGA mass loss at $283 \sim 435^{\circ} \mathrm{C}$ shown in Fig. 2, the ion current spectra for the monitored $\mathrm{m} / \mathrm{z}$ values, such as $\mathrm{m} / \mathrm{z}=14,16,17,18,28,32,44$, generally show a synergistic increase in integral area values in various temperature ranges. This distinction is taken as evidence that the synergistically increased mass loss is associated with these spectra.

The authors further highlight an important feature of the m/z 30 spectra (Fig. 6b), where considerably more of this gas released at $150 \sim 500{ }^{\circ} \mathrm{C}$ when lignin alone was pyrolyzed than when the lignin was blended with collagen. In lignin (which has no nitrogen) m/z 30 was formaldehyde $\left(\mathrm{OCH}_{2}\right)$, which decomposed from hydroxymethylene groups $\left(-\mathrm{CH}_{2} \mathrm{OH}\right)$ in the phenyl propane lateral chains, ester and carboxylic acid groups. While, its emission decreased evidently in the temperature over than $500{ }^{\circ} \mathrm{C}$ (Fig. 6b). Thus, these results indicated that the collagen interacted with the lignin in such manner as to push back the thermal cracking of related functional groups.

In the literature, a number of authors have monitored the pyrolytic of lignin (alone) or collagen (alone), although none others have been found amongst referred papers who have appraised the 
pyrolytic combination of the blend. In the TGA-MS literature, these nine $\mathrm{m} / \mathrm{z}$ values have been attributed to the fragments listed in Table 6; along with the functional groups within lignin and collagen that release pyrolytic gas products. Per Shen et al. [30] and others [31-33], the pyrolytic devolatilization step of lignin commences with the cleavage of hydroxyl groups and ether groups, leading to the formation of $\mathrm{H}_{2} \mathrm{O}$ and formaldehyde. Then, with increasing temperature, profound degradation of the numerous carboxyl, carbonyl, ether groups and methoxyl groups proceeds, releasing such volatiles as $\mathrm{CO}, \mathrm{CO}_{2}$, methanol and methane. These can also include aromatic compounds such as phenolics and alkyl aromatics. Then at higher temperature, secondary reactions commence, which in free radicals couple together. For example, cracking the methoxy group in guaiacye-type compounds may release such derivatives such as phenol-, cresol-, and catechol-types, along with the low molecular weight free radicals $\left(\mathrm{CH}_{2}{ }^{\circ}, \mathrm{CH} 3 \cdot\right.$, and $\mathrm{CH}$ :) and volatile species $\left(\mathrm{CO}, \mathrm{CO}_{2}\right.$ and $\left.\mathrm{CH}_{4}\right)$ [30].

As previously mentioned, collagen is comprised of amino acid, including glycine (Gly), proline (Pro), alanine (Ala), hydroxyproline (Hyp), glutamic acid (Glu), and others. Pyrolysis of amino acid can cause deamination, homolysis of the side chains, dimerisation and decarboxylation reactions, and these decomposition pathways can yield such volatiles as $\mathrm{H}_{2}, \mathrm{H}_{2} \mathrm{O}, \mathrm{CO}, \mathrm{HCN}, \mathrm{NH}_{3}$, methane, and $\mathrm{CO}_{2}$, etc. [34,35].

In light of Fig. 2, Table 5, and pertinent literature, the authors herein propose that the pyrolysis of lignin-collagen blends could be characterized by three temperature regions. The first region, below about $250 \sim 283^{\circ} \mathrm{C}$, was distinguished by the thermal splitting of $\gamma$-carbon ending with hydroxyl group, ester or carboxylic groups on the phenyl propane lateral chains. This led to a synergistic diminishing of $\mathrm{H}_{2} \mathrm{O}$, formaldehyde and methanol emission. During the second section, dehydration, with some decarboxylation, decarboxylation and deamination reactions were enhanced simultaneously, with the aromatic rings remaining essentially intact between 250 and $400{ }^{\circ} \mathrm{C}$. The presence of collagen not only activate the cleavage of $\beta$-alkyl aryl ether and $\alpha$-alkyl aryl ether, but also require less energy to generate free radicals as evidence from results of the calculation of the apparent activation energy listed in section 3.2. Then at yet higher pyrolysis temperatures above about $400 \sim 500{ }^{\circ} \mathrm{C}$, the collagen and lignin together symbiotically impeded the release of these low-m/z species especially $\mathrm{H}_{2} \mathrm{O}, \mathrm{CO}, \mathrm{CO}_{2}$, and methanol. In this temperature region, the two biomaterials together appeared to yield more highly-condensed aromatic rings. 
This facilitated the accumulation of residual char, which was favorable for pyroliticallyenhanced binders such as these.

\section{Conclusions}

When lignin and collagen were blended together, they exhibited a synergistic pyrolytic stability. The mass loss and low-molecular weight volatiles released from the blends was generally less than that which would occur from the mathematical (normalized) sum of these two biomaterials if they had not interacted. The synergistic interaction was perceived as important when using these biomaterials as pyrolytically-enhanced binders.

\section{Acknowledgments}

The authors gratefully acknowledge the support from Priority Academic Program Development of Jiangsu Higher Education Institutions (No. 1105007001), Research Fund for Taihu Lake Pollution Control of Jiangsu Province (No. TH2012207), Research and Innovation Project for College Graduates of Jiangsu Province (No. CXLX110129), and US Department of Agriculture grant USDA NIFA 2011-67009-20049.

\section{Appendix A. Supplementary data}

Supplementary data associated with this article can be found, in the online version, and includes (S1) Representative TGA mass loss curves, (S2) Representative DTG mass loss curves, (S3) non-isothermal reaction rate curves, (S4) Weibull method linear fitting plots, (S5) FlynnWall-Ozawa Arrhenius-type plots, (S6) Pyrolysis product evolution curves.

\section{References}

[1] P. Azadi, O.R. Inderwildi, R. Farnood, D.A. King, Liquid fuels, hydrogen and chemicals from lignin: A critical review, Renew. Sust. Energ. Rev. 21(2013) 506-523.

[2] M.R. Lumadue, F.S. Cannon, N.R. Brown, Lignin as both fuel and fusing binder in briquetted anthracite fines for foundry coke substitute, Fuel. 97(2012) 869-875. 
[3] Z. Li, W. Zhao, B. Meng, C. Liu, Q. Zhu, G. Zhao, Kinetic study of corn straw pyrolysis: comparison of two different three-pseudocomponent models, Bioresource Technol. 99(2008) 7616-7622.

[4] P.F. Britt, A.C. Buchanan III, K.B. Thomas, S. Lee, Pyrolysis mechanisms of lignin: surfaceimmobilized model compound investigation of acid-catalyzed and free-radical reaction pathways, J. Anal. Appl. Pyrol. 33(1995) 1-19.

[5] N. Worasuwannarak, T. Sonobe, W. Tanthapanichakoon, Pyrolysis behaviors of rice straw, rice husk, and corncob by TG-MS technique, J. Anal. Appl. Pyrol. 78(2007) 265-271.

[6] O. Faix, Hamburg, E. Jakab, F. Till, T. Székely, Budapest, Study on loss mass thermal degradation products of milled wood lignins by thermogravimetry-mass-spectrometry, Wood Sci. Technol. 22(1988) 323-334.

[7] R.K. Sharma, J.B. Wooten, V.L. Baliga, X. Lin, W.G. Chan, M.R. Hajaligol, Characterization of chars from pyrolysis of lignin, Fuel. 83(2004) 1469-1482.

[8] H. Haykiri-Acma, S. Yaman, Interaction between biomass and different rank coals during copyrolysis, Renew. Energ. 35(2010) 288-292.

[9] A.A. Salema, M.T. Afzal, F. Motasemi, Is there synergy between carbonaceous material and biomass during conventional pyrolysis? A TG-FTIR approach, J. Anal. Appl. Pyrol. 105(2014) 217-226.

[10] F. Cong, B.G. Diehl, J.L. Hill, N.R. Brown, M. Tien, Covalent bond formation between amino acids and lignin: Cross-coupling between proteins and lignin, Phytochemistry. 96(2013) $449-456$.

[11] J.T. Fox, F.S. Cannon, N.R. Brown, H. Huang, J.C. Furness, Comparison of a new, green foundry binder with conventional foundry binders, Int. J. Adhes. Adhes. 34(2012) 38-45.

[12] C. Nieto-Delgado, F.S. Cannon, P.D. Paulsen, J.C. Furness, R.C. Voigt, J.R. Pagnotti, Bindered anthracite briquettes as fuel alternative to matellurgical coke: Full scale performance in cupola furnaces, Fuel. 121(2014) 39-47. 
[13] Y. Wang, F.S. Cannon, M. Salama, J. Goudzwarrd, J.C. Furness, Characterization of hydrocarbon emissions from green sand foundry core binders by analytical pyrolysis, Environ. Sci. Technol. 41(2007) 7922-7927.

[14] R.A. Fenner, J.O. Lephardt, Examination of the thermal decomposition of kraft pine lignin by Fourier Transform Infrared evolved gas analysis, J. Agric. Food Chem. 29(1981) 846-849.

[15] R.K. Sharma, W.G. Chan, M.R. Hajaligol, Product compositions from pyrolysis of some aliphatic $\alpha$-amino acids, J. Anal. Appl. Pyrol. 75(2006) 69-81.

[16] S. Choi, J. Ko, Analysis of cyclic pyrolysis products formed amino acid monomer, J. Chromatogr. A. 1218(2011) 8443-8455.

[17] N.F. Haidar, J.M. Patterson, M. Moors, W.T. Smith, Jr., Effects of structure on pyrolysis gases from amino acids, J. Agric. Food Chem. 29(1981) 163-165.

[18] J.E. Eastoe, A.A. Leach, Recent advances in gelatin and glue research, Pergamon Press, New York, 1958.

[19] R.G.D. Steel, J.H. Torrie, D.A. Dickey, Principles and procedures of statistics: a biometrical approach, Second ed., McGRAW-HILL, INC., New York, 1980.

[20] A.W. Coats, J.P. Redfern, Kinetic parameters from thermogravimetric data, Nature. 201(1964) 68-69.

[21] H.E. Kissinger, Reaction kinetics in differential thermal analysis, Anal. Chem. 29(1957) 1702-1706.

[22] Y.F. Huang, W.H. Kuan, P.T. Chiueh, S.L. Lo, A sequential method to analyze the kinetics of biomass pyrolysis, Bioresource Technol. 102(2011) 9241-9246.

[23] B. Janković, Kinetic analysis of isothermal decomposition process of sodium bicarbonate using the Weibull probability function - estimation of density distribution functions of the apparent activation energies, Metall mater trans B. 40B(2009) 712-726.

[24] J.H. Flynn, The 'Temperature Integral' - its use and abuse, Thermochim. Acta. 300 (1997) 83-92. 
[25] F.P. Petrocelli, M.T. Klein, Model reaction pathways in Kraft lignin pyrolysis, Macromolecules. 17(1984) 161-169.

[26] W. Tang, C. Wang, D. Chen, An investigation of the pyrolysis kinetics of some aliphatic amino acids, J. Anal. Appl. Pyrol. 75(2006) 49-53.

[27] R. Parthasarathi, R.A. Romero, A. Redondo, S. Gnanakaran, Theoretical study of the remarkably diverse linkages in lignin, J. Phys. Chem. Lett. 2(2011) 2660-2666.

[28] T. Faravelli, A. Frassoldati, G. Migliavacca, E. Ranzi, Detailed kinetic modeling of the thermal degradation of lignins, Biomass. Bioenerg. 34(2010) 290-302.

[29] E. Avni, R.W. Coughlin, Kinetic analysis of lignin pyrolysis using non-isothermal TGA data, Thermochim. Acta. 90(1985) 157-167.

[30] D.K. Shen, S. Gu, K.H. Luo, S.R. Wang, M.X. Fang, The pyrolytic degradation of woodderived lignin from pulping process, Bioresource Technol. 101(2010) 6136-6146.

[31] R.J. Evans, T.A. Milne, M.N. Soltys, Direct mass-spectrometric studies of the pyrolysis of carbonaceous fuels Ш. Primary pyrolysis of lignin, J. Anal. Appl. Pyrol. 9(1986) 207-236.

[32] E. Jakab, O. Faix, F. Till, Thermal decomposition of milled wood lignins studied by thermogravimetry/mass spectrometry, J. Anal. Appl. Pyrol.40-41(1997) 171-186.

[33] Q. Liu, S. Wang, Y. Zheng, Z. Luo, K. Cen, Mechanism study of wood lignin pyrolysis by using TG-FTIR analysis, J. Anal. Appl. Pyrol. 82 (2008) 170-177.

[34] M.A. Ratcliff, Jr., E.E. Medley, P.G. Simmonds, Pyrolysis of amino acids. Mechanistic considerations, J. Org. Chem. 39(1974) 1481-1490.

[35] Q. Ren, C. Zhao, X. Chen, L. Duan, Y. Li, C. Ma, NO $\chi$ and N2O precursors (NH3 and $\mathrm{HCN}$ ) from biomass pyrolysis: co-pyrolysis of amino acids and cellulose, hemicellulose and lignin, P. Combust. Inst. 33(2011) 1715-1722. 

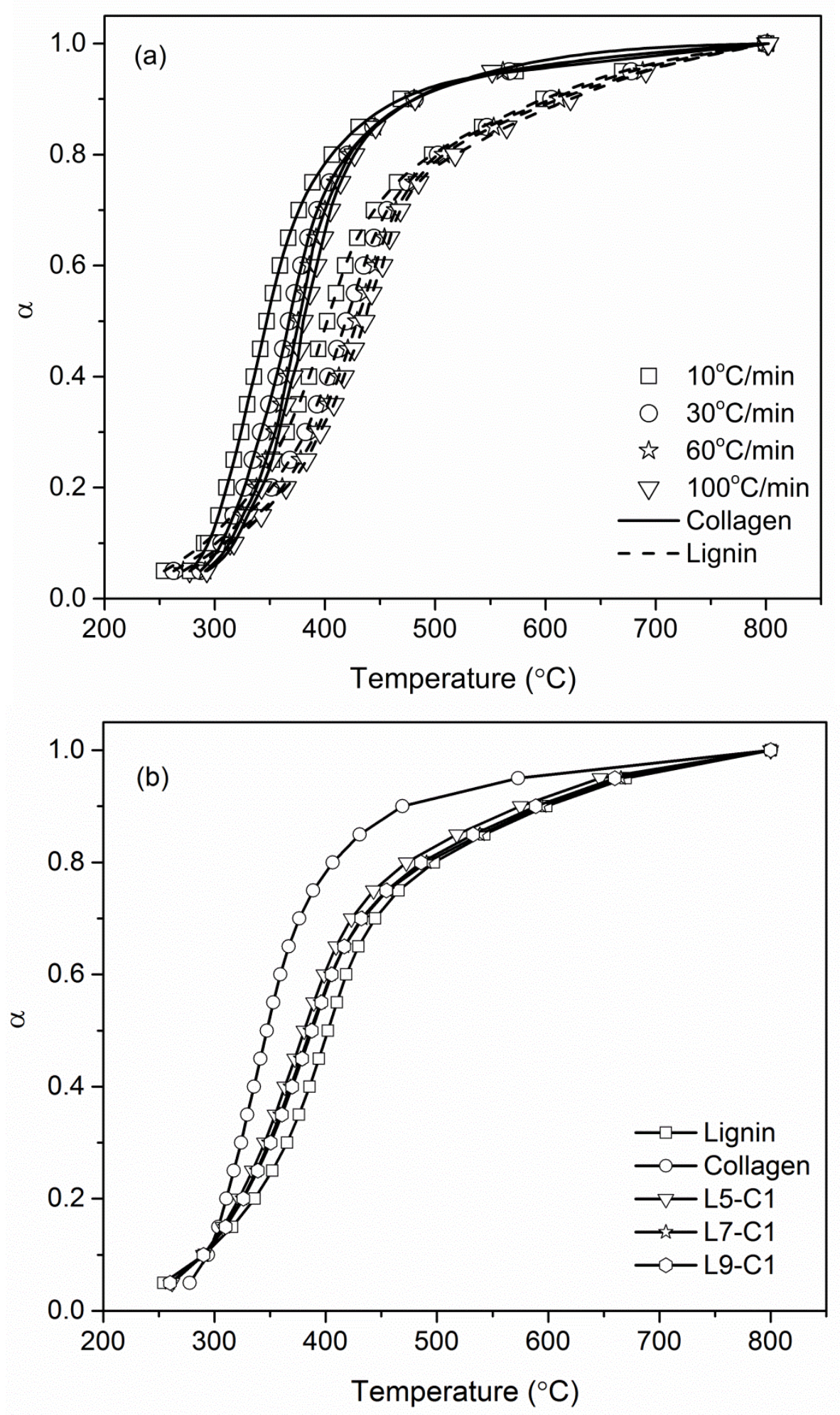

Fig. 1. The non-isothermal conversion curves for (a) lignin and collagen pyrolyzed at different heating rates; (b) lignin, collagen and their blends pyrolyzed at a heating rate of $10{ }^{\circ} \mathrm{C} / \mathrm{min}$. 


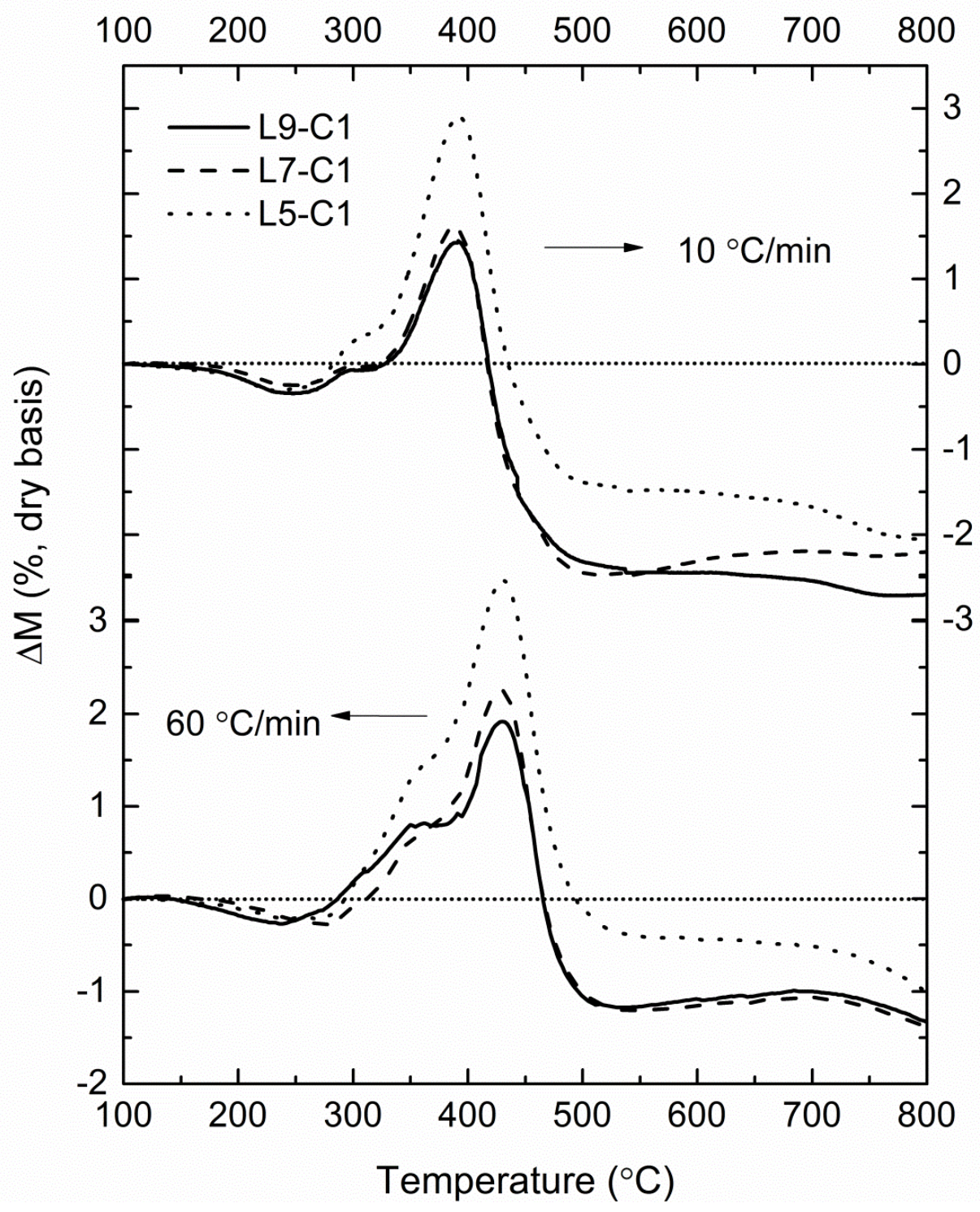

Fig. 2. Variation of mass loss fraction for lignin-collagen blends at heating rate of $10{ }^{\circ} \mathrm{C} / \mathrm{min}$ and $60{ }^{\circ} \mathrm{C} / \mathrm{min}$. 


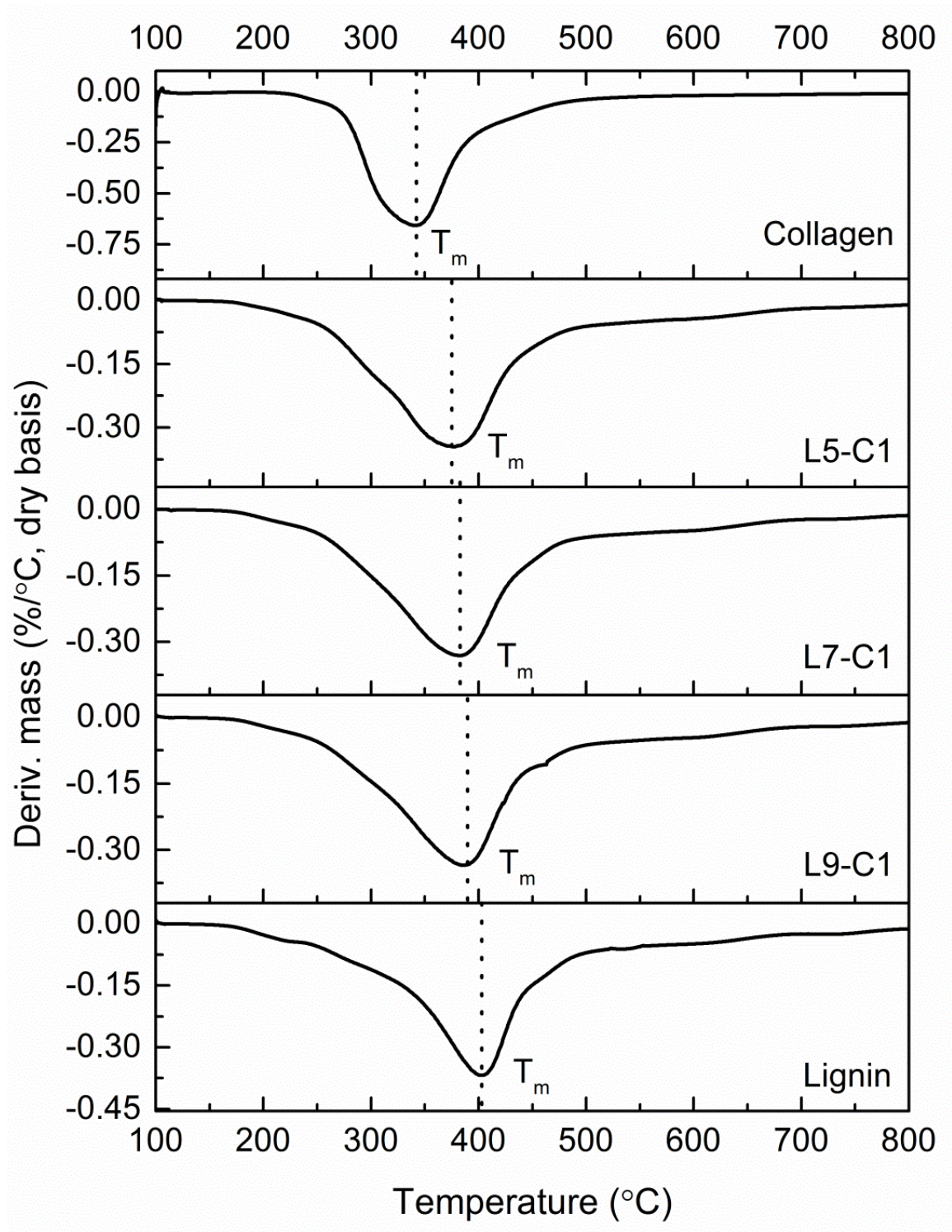

Fig. 3. Differential thermogravimetry curves for lignin, collagen and their blends pyrolyzed at a heating rate of $10^{\circ} \mathrm{C} / \mathrm{min}$. 


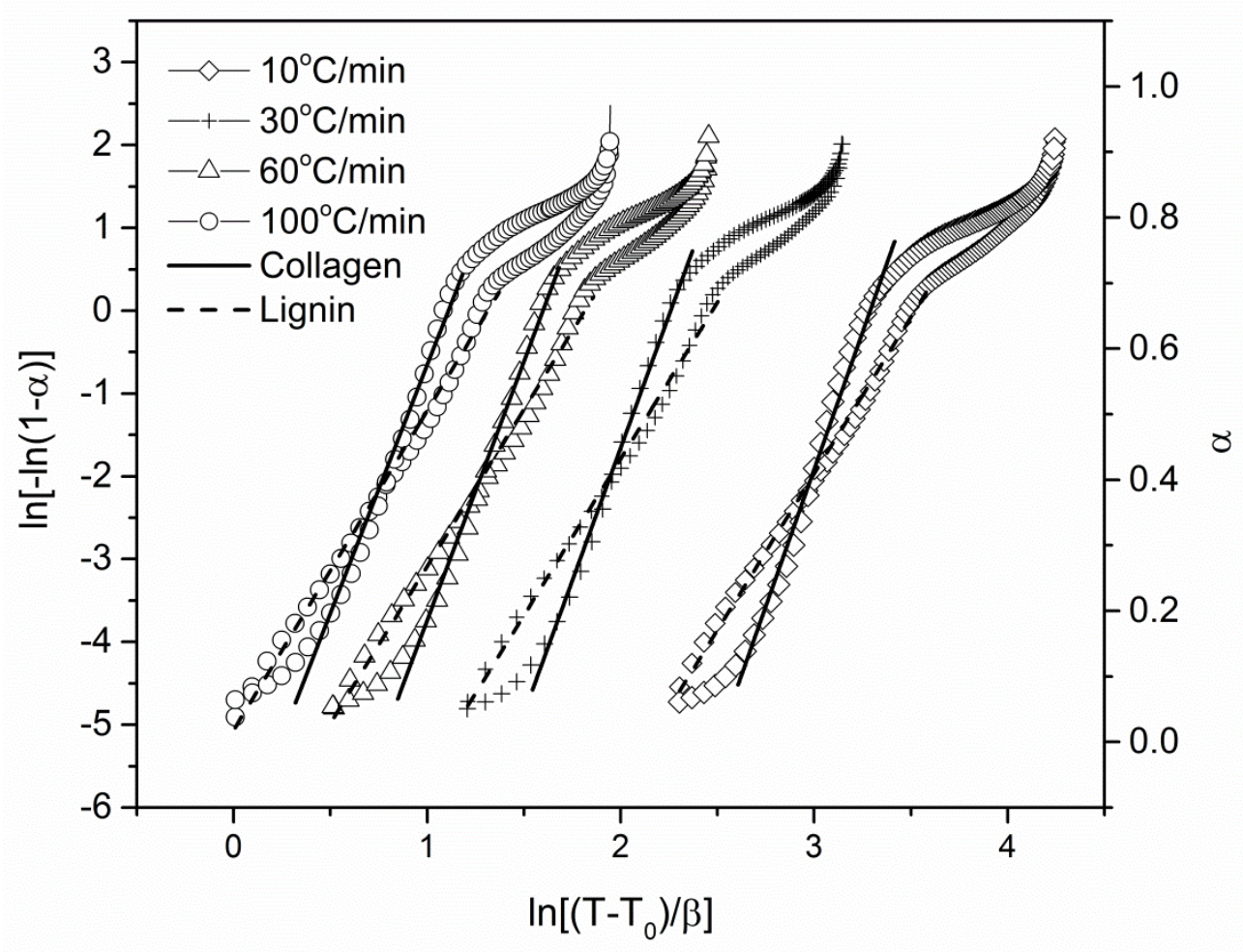

Fig. 4. Weibull method: Dependence of $\ln [-\ln (1-\alpha)]$ versus $\ln \left[\left(T-T_{0}\right) / \beta\right]$ for lignin and collagen pyrolysis in major pyrolysis stage. 


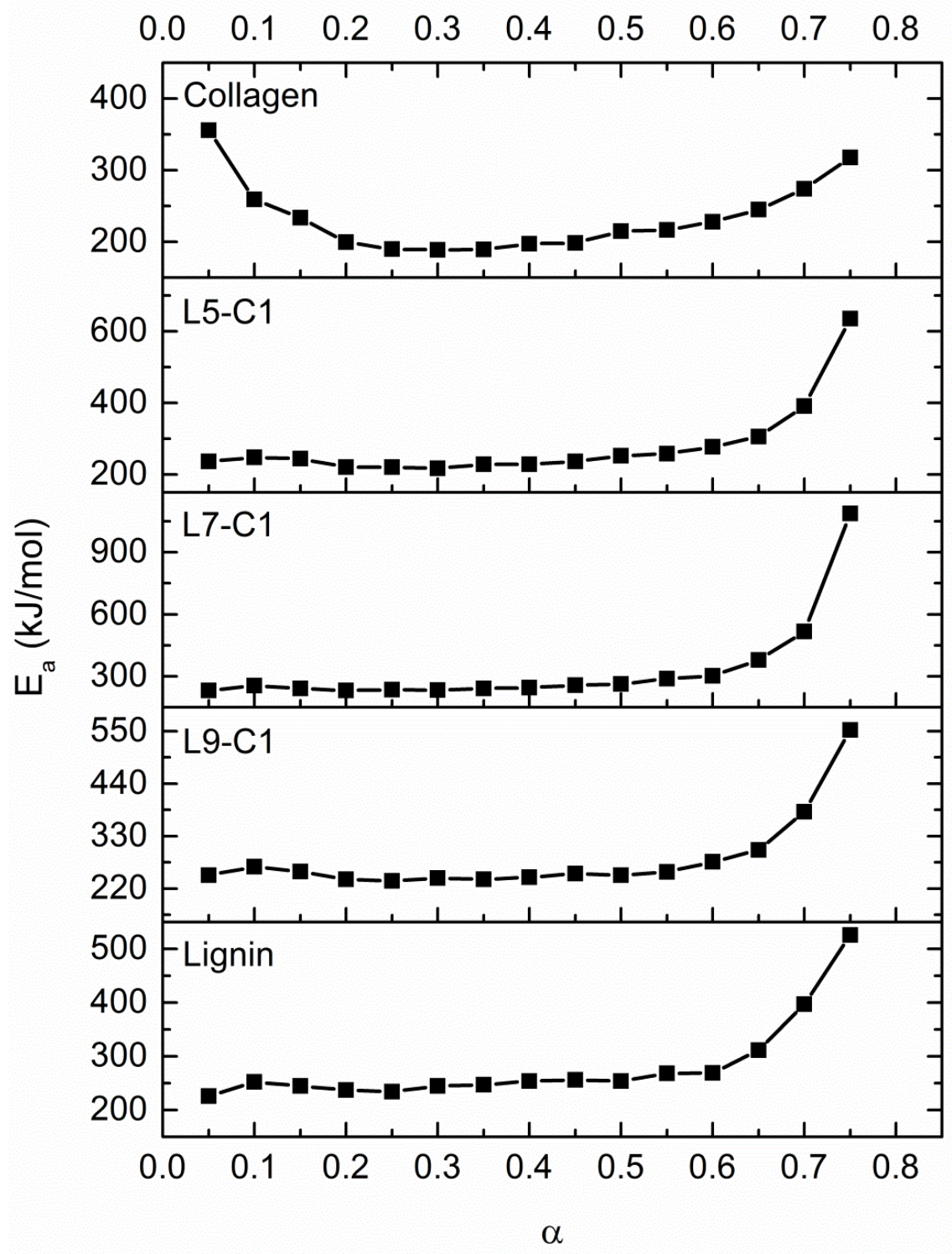

Fig. 5. The dependence of the apparent activation energies on the degree of conversion for lignin, collagen, and their blends, calculated by Flynn-Wall-Ozawa method. 

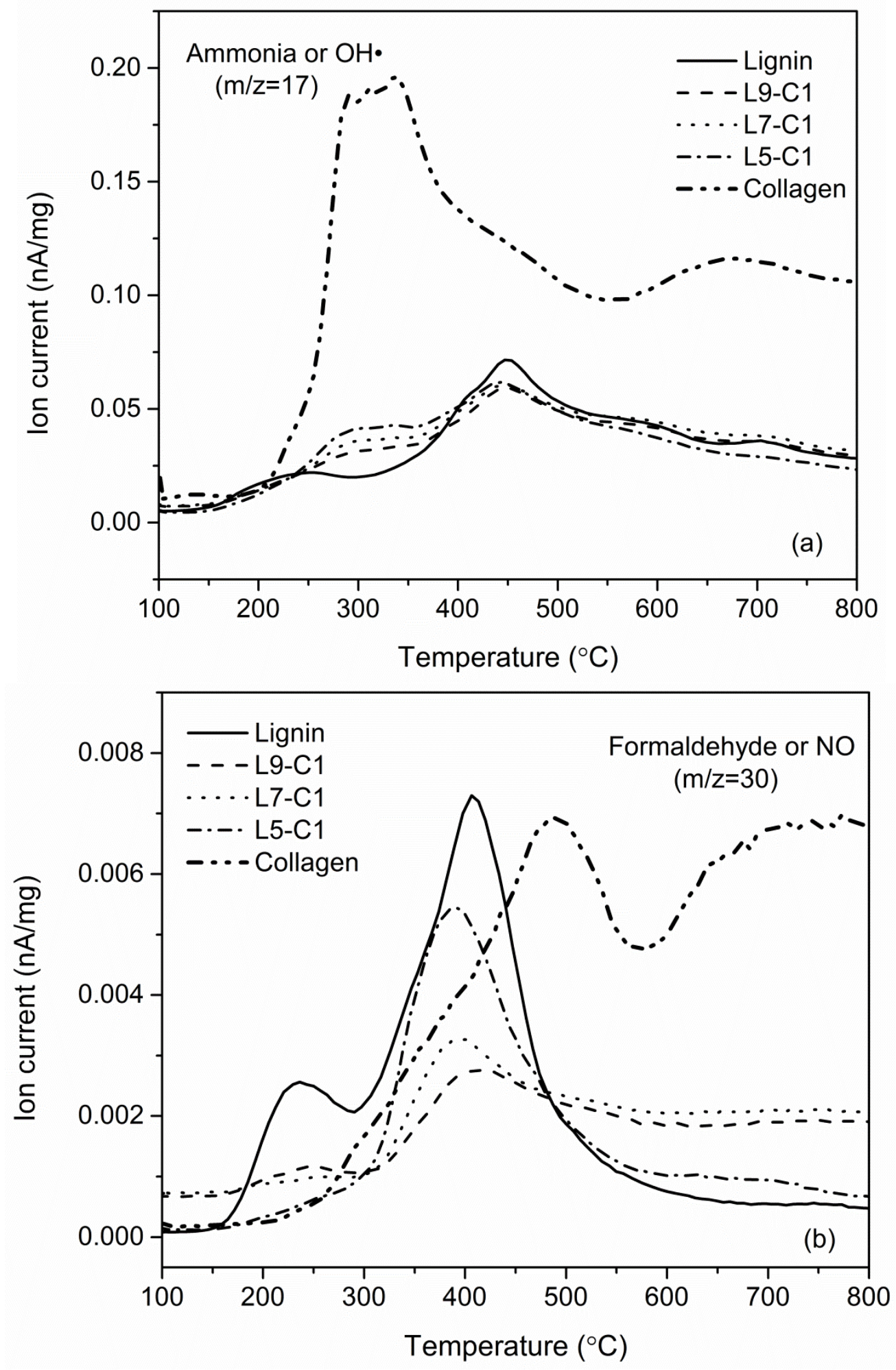

Fig. 6. Comparison of pyrolysis product evolution curves for lignin, collagen and their blends for $10{ }^{\circ} \mathrm{C} / \mathrm{min}$ TGA runs. 
Table 1 Kinetic methods used for apparent activation energy calculation in this study.

\begin{tabular}{|c|c|c|c|}
\hline Method & Apparent activation energy protocols & $\mathrm{x}$-axis & $y$-axis \\
\hline Kissinger & $\begin{array}{c}\ln \left(\frac{\beta}{T_{m}^{2}}\right)=\ln \left(\frac{\mathrm{A} R}{E_{a}}\right)-\frac{E_{a}}{R T_{m}}, \\
\text { where } \mathrm{n}=0.1368 \exp \left[5.3635\left(1-\alpha_{m}\right)\right], \text { for } \mathrm{n} \neq 1 ; \\
\text { and } \mathrm{A}=\frac{\beta \mathrm{E}_{\mathrm{a}}}{\mathrm{RT}_{m}^{2} \mathrm{n}\left(1-\alpha_{\mathrm{m}}\right)^{\mathrm{n}-1}} \mathrm{e}^{\mathrm{E}_{\mathrm{a}} / \mathrm{RT}_{\mathrm{m}}}\end{array}$ & $1 / T_{m}$ & $\ln \left(\beta / \mathrm{T}_{\mathrm{m}}^{2}\right)$ \\
\hline Weibull & $\begin{array}{c}\ln \left(\frac{1}{\eta}\right)=\text { constant }-\frac{\mathrm{E}_{\mathrm{a}}}{\mathrm{RT}_{\mathrm{p}}} \\
\text { Where } \mathrm{T}_{\mathrm{p}}=\mathrm{T}_{0}+\beta \cdot \eta[(\theta-1) / \theta]^{1 / \theta} \\
\text { and } \theta \text { and } \eta \text { are derived from } \\
\ln [-\ln (1-\alpha)]=\theta \ln \left(\frac{1}{\eta}\right)+\theta \ln \left[\frac{\left(\mathrm{T}-\mathrm{T}_{0}\right)}{\beta}\right]\end{array}$ & $1 / T_{p}$ & $\ln \left(\frac{1}{\eta}\right)$ \\
\hline Flynn-Wall-Ozawa & $\log \beta=\log \left[A E_{a} /\left(R \int_{0}^{\alpha} \frac{d \alpha}{f(\alpha)}\right)\right]-2.315-0.4567 \frac{E_{a}}{R T}$ & $1 / T$ & $\log \beta$ \\
\hline
\end{tabular}

$\beta$, linear heating rate; $\mathrm{T}_{\mathrm{m}}$, temperature corresponding to the maximum reaction rate obtained from differential thermogravimetry curves; $\mathrm{A}$, pre-exponential factor; $R$, ideal gas constant; $E_{a}$, apparent activation energy; $\mathrm{n}$, reaction order; $\alpha_{m}$, maximum value of relative pyrolysis mass loss conversion $\alpha ; T_{0}$, starting temperature; $\theta$, shape parameter; $\eta$, scale parameter; $T_{p}$, a function of $\theta, \eta$, and $\beta ; 1 / \eta$, corresponding rate constant of Weibull distribution function; $f(\alpha)$, a conversion function that depends on the reaction model used and controlling mechanism. 
Table 2 The peak temperature and conversion rate, as well as kinetic parameters obtained from Kissinger method at different heating rates for lignin, collagen and the blends pyrolysis.

\begin{tabular}{|c|c|c|c|c|c|c|c|c|c|c|}
\hline Sample & $\beta\left({ }^{\circ} \mathrm{C} / \mathrm{min}\right)$ & "Reps & $\mathrm{m}_{\mathrm{R}} \%{ }^{*}$ & $\alpha_{\mathrm{m}}$ & $\mathrm{T}_{\mathrm{m}}\left({ }^{\circ} \mathrm{C}\right)$ & $\mathrm{n}$ & $\mathrm{A}(1 / \mathrm{min})$ & $\mathrm{E}_{\mathrm{a}}(\mathrm{kJ} / \mathrm{mol})$ & $\Delta M$ at $\mathrm{T}_{\mathrm{m}}(\%)$ & $\Delta M$ at $435 \sim 800{ }^{\circ} \mathrm{C}(\%)$ \\
\hline \multirow{4}{*}{ Lignin } & 10 & 2 & 41.52 & 0.51 & 403.6 & 1.88 & $6.27 \mathrm{E}+15$ & \multirow{4}{*}{208} & - & - \\
\hline & 30 & 3 & 41.44 & 0.54 & 425.1 & 1.62 & $5.64 \mathrm{E}+15$ & & - & - \\
\hline & 60 & 3 & 40.29 & 0.56 & 437.3 & 1.48 & $5.90 \mathrm{E}+15$ & & - & - \\
\hline & 100 & 2 & 40.14 & 0.58 & 445.7 & 1.34 & $6.38 \mathrm{E}+15$ & & - & - \\
\hline \multirow{4}{*}{ L9-C1 } & 10 & 3 & 42.56 & 0.49 & 385.4 & 2.12 & $1.90 \mathrm{E}+15$ & \multirow{4}{*}{191} & 1.4 & -2.7 \\
\hline & 30 & 2 & 41.53 & 0.52 & 410.7 & 1.76 & $1.41 \mathrm{E}+15$ & & - & - \\
\hline & 60 & 2 & 39.63 & 0.53 & 419.8 & 1.75 & $1.74 \mathrm{E}+15$ & & 1.8 & -1.4 \\
\hline & 100 & 2 & 39.44 & 0.56 & 428.7 & 1.46 & $1.84 \mathrm{E}+15$ & & - & - \\
\hline \multirow{4}{*}{ L7-C1 } & 10 & 2 & 41.72 & 0.48 & 382.0 & 2.25 & $6.20 \mathrm{E}+14$ & \multirow{4}{*}{179} & 1.5 & -2.5 \\
\hline & 30 & 2 & 40.89 & 0.50 & 403.1 & 1.98 & $5.92 \mathrm{E}+14$ & & - & - \\
\hline & 60 & 2 & 39.14 & 0.55 & 420.3 & 1.50 & $4.88 \mathrm{E}+14$ & & 2.1 & -1.4 \\
\hline & 100 & 3 & 38.68 & 0.57 & 426.4 & 1.39 & $6.00 \mathrm{E}+14$ & & 一 & - \\
\hline \multirow{4}{*}{ L5-C1 } & 10 & 3 & 40.82 & 0.49 & 378.1 & 2.15 & $5.06 \mathrm{E}+13$ & \multirow{4}{*}{175} & 2.6 & -2.1 \\
\hline & 30 & 2 & 38.86 & 0.51 & 399.8 & 1.95 & $5.04 \mathrm{E}+13$ & & - & - \\
\hline & 60 & 2 & 37.95 & 0.55 & 414.9 & 1.54 & $4.83 \mathrm{E}+13$ & & 3.0 & -1.0 \\
\hline & 100 & 2 & 36.49 & 0.58 & 424.5 & 1.32 & $5.16 \mathrm{E}+13$ & & - & - \\
\hline Collagen & 10 & 3 & 24.89 & 0.45 & 341.0 & 2.62 & $4.34 \mathrm{E}+13$ & 164 & - & - \\
\hline
\end{tabular}




\begin{tabular}{|c|c|c|c|c|c|c|c|c|c|c|}
\hline \multirow{2}{*}{} & 30 & 4 & 20.90 & 0.51 & 368.4 & 1.87 & $3.02 \mathrm{E}+13$ & & - & - \\
\cline { 2 - 7 } & 60 & 4 & 19.92 & 0.52 & 377.6 & 1.84 & $3.81 \mathrm{E}+13$ & & - \\
\cline { 2 - 7 } & 100 & 5 & 17.74 & 0.52 & 383.2 & 1.79 & $4.82 \mathrm{E}+13$ & & - & - \\
\hline
\end{tabular}

$\beta$, linear heating rate; ${ }^{\#}$ Reps, number of replicates; ${ }^{*} \mathrm{~m}_{\mathrm{R}}$, total pyrolysis mass remaining at $800^{\circ} \mathrm{C} ; \alpha_{m}$, maximum value of relative pyrolysis mass loss conversion; $\mathrm{T}_{\mathrm{m}}$, temperature corresponding to the maximum reaction rate obtained from differential thermogravimetry curves; $\mathrm{n}$, reaction order; A, pre-exponential factor; $E_{a}$, apparent activation energy; $\Delta M$, the difference of mass loss fractions for lignin-collagen blends between the experimental values and the calculated values. 
Table 3 The parameters values of the Weibull distribution function for the major pyrolysis stage of lignin, collagen, and their blends pyrolysis, at different heating rates.

\begin{tabular}{|c|c|c|c|c|c|c|}
\hline Sample & $\beta\left({ }^{\circ} \mathrm{C} / \mathrm{min}\right)$ & $\theta$ & $\eta$ & $1 / \eta(1 / \mathrm{min})$ & $\mathrm{r}^{2}$ & $\mathrm{E}_{a}(\mathrm{~kJ} / \mathrm{mol})$ \\
\hline \multirow{4}{*}{ Lignin } & 10 & 3.746 & 34.004 & 0.029 & 0.994 & \multirow{4}{*}{247} \\
\hline & 30 & 3.712 & 12.025 & 0.083 & 0.993 & \\
\hline & 60 & 3.720 & 6.229 & 0.161 & 0.992 & \\
\hline & 100 & 3.780 & 3.777 & 0.265 & 0.993 & \\
\hline \multirow{4}{*}{ L9-C1 } & 10 & 4.249 & 31.714 & 0.032 & 0.998 & \multirow{4}{*}{244} \\
\hline & 30 & 4.364 & 11.213 & 0.089 & 0.999 & \\
\hline & 60 & 4.324 & 5.781 & 0.173 & 0.999 & \\
\hline & 100 & 4.139 & 3.555 & 0.281 & 0.992 & \\
\hline \multirow{4}{*}{ L7-C1 } & 10 & 4.210 & 31.702 & 0.032 & 0.997 & \multirow{4}{*}{243} \\
\hline & 30 & 4.238 & 11.233 & 0.089 & 0.994 & \\
\hline & 60 & 4.211 & 5.799 & 0.172 & 0.994 & \\
\hline & 100 & 4.155 & 3.545 & 0.282 & 0.992 & \\
\hline \multirow{4}{*}{ L5-C1 } & 10 & 4.456 & 30.835 & 0.032 & 0.998 & \multirow{4}{*}{233} \\
\hline & 30 & 4.460 & 10.997 & 0.091 & 0.996 & \\
\hline & 60 & 4.365 & 5.672 & 0.176 & 0.995 & \\
\hline & 100 & 4.442 & 3.461 & 0.289 & 0.995 & \\
\hline \multirow{4}{*}{ Collagen } & 10 & 7.162 & 26.201 & 0.038 & 0.993 & \multirow{4}{*}{194} \\
\hline & 30 & 6.743 & 9.438 & 0.106 & 0.996 & \\
\hline & 60 & 6.458 & 4.923 & 0.203 & 0.993 & \\
\hline & 100 & 6.104 & 3.036 & 0.329 & 0.989 & \\
\hline
\end{tabular}

$\beta$, linear heating rate; $\theta$, shape parameter; $\eta$, scale parameter; $1 / \eta$, rate constant of Weibull distribution function; $\mathrm{r}^{2}$, linear correlation coefficient; $E_{a}$, apparent activation energy. 
Table 4 Comparison of apparent activation energies determined from various methods.

\begin{tabular}{|c|c|c|c|c|}
\hline Sample & $\begin{array}{c}\text { Kissinger } \mathrm{E}_{a} \\
(\mathrm{~kJ} / \mathrm{mol}) \\
(0.45<\alpha<0.58)\end{array}$ & $\begin{array}{c}\text { Weibull } \mathrm{E}_{a} \\
(\mathrm{~kJ} / \mathrm{mol}) \\
(0.01<\alpha<0.7)\end{array}$ & $\begin{array}{c}\text { Flynn-Wall-Ozawa } \mathrm{E}_{a} \\
(\mathrm{~kJ} / \mathrm{mol}) \\
(0.2<\alpha<0.45)\end{array}$ & $\begin{array}{c}\text { Flynn-Wall-Ozawa } \mathrm{E}_{a} \\
(\mathrm{~kJ} / \mathrm{mol}) \\
(0.45<\alpha<0.55)\end{array}$ \\
\hline Lignin & 208 & 247 & 245 & 259 \\
\hline L9-C1 & 191 & 244 & 242 & 268 \\
\hline L7-C1 & 179 & 243 & 240 & 249 \\
\hline L5-C1 & 175 & 233 & 225 & 210 \\
\hline Collagen & 164 & 194 & 194 & 251 \\
\hline
\end{tabular}

$E_{a}$, apparent activation energy.

Table 5 The integral area values as determined by TGA-MS in various temperature ranges.

\begin{tabular}{|c|c|c|c|c|c|c|c|c|}
\hline $\mathrm{m} / \mathrm{z}$ & Species & $\begin{array}{c}\text { Temperature } \\
\text { Range }\left({ }^{\circ} \mathrm{C}\right)\end{array}$ & Lignin & Collagen & L5-C1 & Math $^{*}$ & $\Delta \mathrm{I}^{* * *}$ & $\Delta \mathrm{e}^{* * * *}$ \\
\hline 14 & $\mathrm{CH}_{2}:$ & $150 \sim 250$ & 0.01 & 0.01 & 0.01 & 0.01 & -0.01 & -0.38 \\
\hline
\end{tabular}




\begin{tabular}{|c|c|c|c|c|c|c|c|c|}
\hline & & $250 \sim 283$ & 0.01 & 0.04 & 0.01 & 0.02 & 0.00 & -0.80 \\
\hline & & $283 \sim 325$ & 0.02 & 0.19 & 0.04 & 0.05 & -0.01 & -2.04 \\
\hline & & $325 \sim 400$ & 0.19 & 0.79 & 0.28 & 0.29 & -0.01 & -1.14 \\
\hline & & $400 \sim 435$ & 0.36 & 0.54 & 0.31 & 0.39 & -0.08 & -14.32 \\
\hline & & $435 \sim 500$ & 0.62 & 1.38 & 0.50 & 0.74 & -0.25 & -22.79 \\
\hline & & $500 \sim 800$ & 1.77 & 7.28 & 1.83 & 2.69 & -0.86 & -17.25 \\
\hline \multirow{7}{*}{15} & \multirow{7}{*}{$\mathrm{CH}_{3}$. } & $150 \sim 250$ & 0.01 & 0.03 & 0.01 & 0.01 & 0.00 & -0.21 \\
\hline & & $250 \sim 283$ & 0.01 & 0.10 & 0.03 & 0.03 & 0.00 & -0.48 \\
\hline & & $283 \sim 325$ & 0.04 & 0.34 & 0.08 & 0.09 & -0.01 & -1.66 \\
\hline & & $325 \sim 400$ & 0.65 & 0.78 & 0.93 & 0.67 & 0.25 & 20.20 \\
\hline & & $400 \sim 435$ & 1.62 & 0.46 & 1.29 & 1.42 & -0.14 & -23.34 \\
\hline & & $435 \sim 500$ & 2.39 & 1.90 & 1.72 & 2.30 & -0.58 & -53.67 \\
\hline & & $500 \sim 800$ & 4.23 & 7.78 & 4.38 & 4.82 & -0.43 & -8.67 \\
\hline \multirow{7}{*}{16} & \multirow{7}{*}{$\mathrm{CH}_{4}$ or $\mathrm{NH}_{2}$. } & $150 \sim 250$ & 0.14 & 0.44 & 0.12 & 0.19 & -0.06 & -3.87 \\
\hline & & $250 \sim 283$ & 0.09 & 1.55 & 0.24 & 0.34 & -0.10 & -17.68 \\
\hline & & $283 \sim 325$ & 0.16 & 4.74 & 0.63 & 0.92 & -0.29 & -40.95 \\
\hline & & $325 \sim 400$ & 0.92 & 8.69 & 1.73 & 2.21 & -0.48 & -38.23 \\
\hline & & $400 \sim 435$ & 1.92 & 2.97 & 1.66 & 2.10 & -0.44 & -75.17 \\
\hline & & $435 \sim 500$ & 3.15 & 5.64 & 2.46 & 3.56 & -1.11 & -102.04 \\
\hline & & $500 \sim 800$ & 6.46 & 21.42 & 6.81 & 8.96 & -2.14 & -42.84 \\
\hline \multirow{5}{*}{17} & \multirow{5}{*}{$\mathrm{NH}_{3}$ or $\mathrm{OH}$. } & $150 \sim 250$ & 1.08 & 1.09 & 0.86 & 1.09 & -0.22 & -13.28 \\
\hline & & $250 \sim 283$ & 0.55 & 3.30 & 0.99 & 1.01 & -0.02 & -4.38 \\
\hline & & $283 \sim 325$ & 0.67 & 7.50 & 1.56 & 1.81 & -0.25 & -35.40 \\
\hline & & $325 \sim 400$ & 1.94 & 11.94 & 3.06 & 3.61 & -0.55 & -43.69 \\
\hline & & $400 \sim 435$ & 1.89 & 4.21 & 1.78 & 2.28 & -0.50 & -85.50 \\
\hline
\end{tabular}




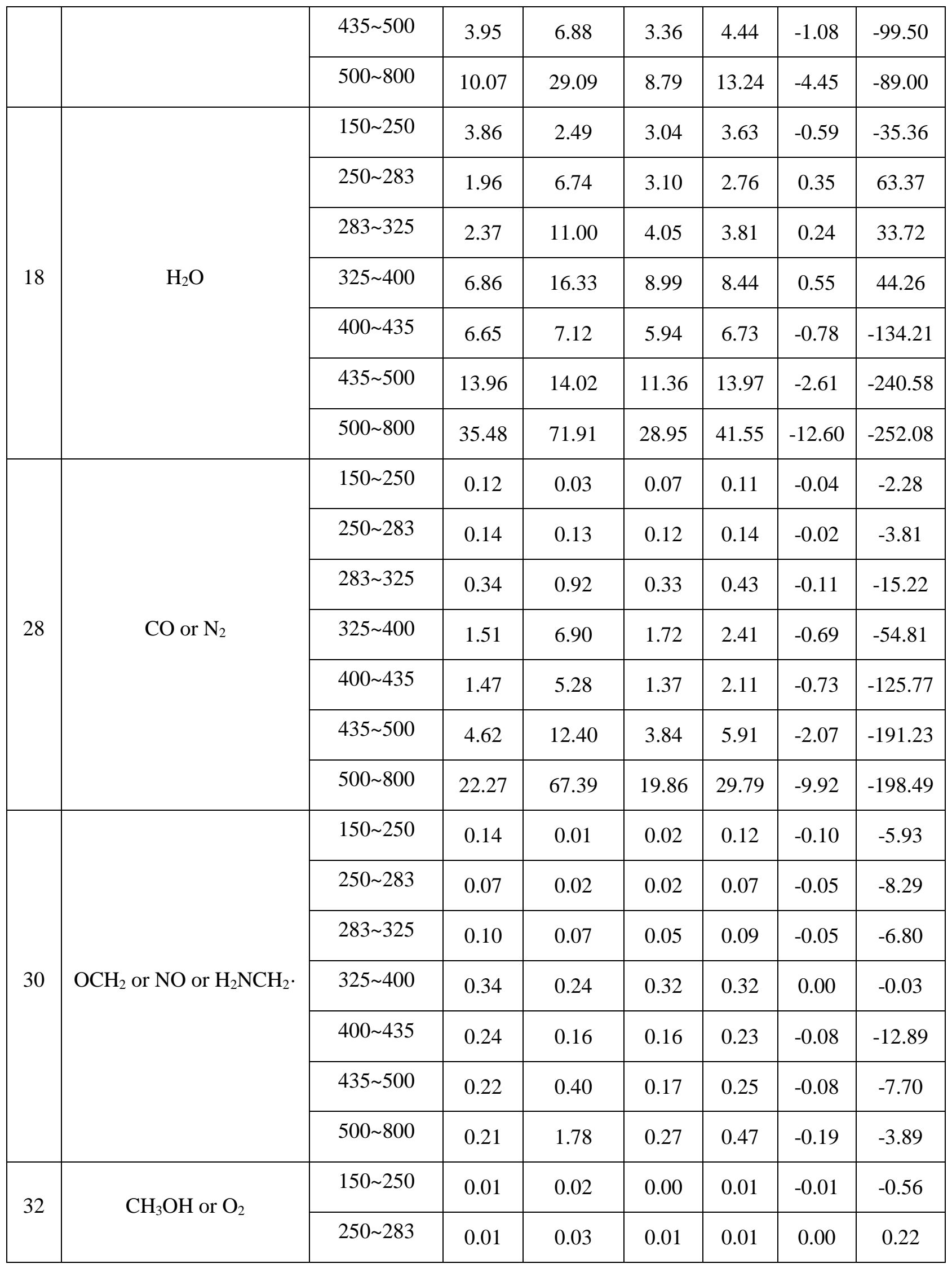




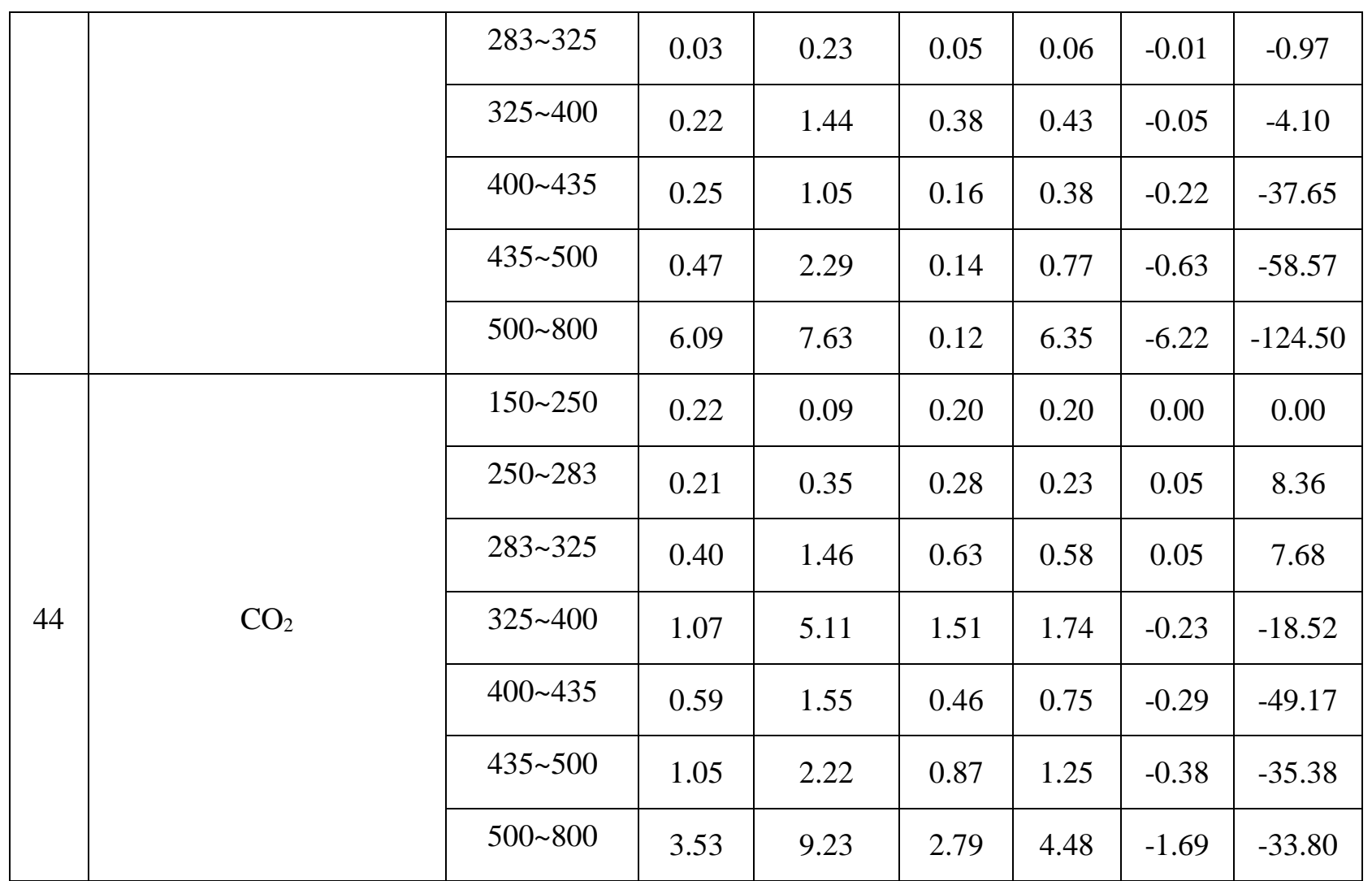

* Math $=5 \times$ (integral area values for Lignin) $/ 6+1 \times($ integral area values for collagen $) / 6$;

${ }^{* *} \Delta \mathrm{I}=$ (integral area values for L5-C1) - Math;

${ }^{* * *} \Delta \mathrm{e}=\Delta \mathrm{I} \times 6000 /($ temperature span) 
Table 6. Major thermal degradation products and radical intermediate of lignin, collagen and their blends as determined by Thermogravimetric analysis-mass spectrometry.

\begin{tabular}{|c|c|c|c|}
\hline \multirow[t]{2}{*}{$\mathrm{m} / \mathrm{z}$} & \multirow{2}{*}{$\begin{array}{l}\text { Formula of } \\
\text { major frag- } \\
\text { ments }\end{array}$} & \multicolumn{2}{|c|}{$\begin{array}{l}\text { Probable contributors (Evans et al., 1986; Jakab et al., 1997; Liu et al., } \\
\qquad \text { 2008; Shen et al., 2010) }\end{array}$} \\
\hline & & Lignin & Collagen \\
\hline 14 & $\mathrm{CH}_{2}$ & $\begin{array}{l}\text { The ionisation fragment of methoxy } \\
\text { groups; the cracking of the methoxy } \\
\text { group in guaiacol-type compounds }\end{array}$ & Methylene group \\
\hline 15 & $\mathrm{CH}_{3}$. & $\begin{array}{l}\text { The ionisation fragment of methoxy } \\
\text { groups; the cracking of the methoxy } \\
\text { group in guaiacol-type compounds }\end{array}$ & Methyl group \\
\hline 16 & $\mathrm{CH}_{4}$ & $\begin{array}{l}\text { Methoxyl substituents in phenolic units; } \\
\text { the rupture of aromatic rings }\end{array}$ & Methyl group \\
\hline 17 & $\mathrm{OH} \cdot$ or $\mathrm{NH}_{3}$ & Hydroxyl groups and ether groups & $\begin{array}{l}\text { Diketopiperazines (DKP) de- } \\
\text { composition and deamination } \\
\text { reaction between imines and } \\
\text { amines }\end{array}$ \\
\hline 18 & $\mathrm{H}_{2} \mathrm{O}$ & $\begin{array}{l}\text { Water evaporation; hydroxyl groups and } \\
\text { ether groups }\end{array}$ & $\begin{array}{l}\text { Water elimination and intra- } \\
\text { molecular condensation }\end{array}$ \\
\hline 28 & $\mathrm{CO}$ & $\begin{array}{l}\text { Alkyl side-chains ending with carbonyl } \\
\text { groups (-CHO); diaryl ether groups and } \\
\text { secondary pyrolysis of formaldehyde or } \\
\text { other free radical coupling reactions at the }\end{array}$ & $\begin{array}{l}\text { Carboxyl, carbonyl and ether } \\
\text { groups; diketopiperazines } \\
\text { (DKP) decomposition }\end{array}$ \\
\hline
\end{tabular}




\begin{tabular}{|c|c|c|c|}
\hline \multirow{2}{*}{30} & HCHO & $\begin{array}{r}\text { high temperature } \\
\text { propane lateral chains and ester or car- } \\
\text { boxylic groups in } \gamma \text {-positions }\end{array}$ & Terminal $-\mathrm{CH}_{2} \mathrm{OH}$ groups \\
\hline 32 & $\begin{array}{c}\mathrm{CH}_{3} \mathrm{OH} \text { or } \\
\mathrm{O}_{2}\end{array}$ & $\begin{array}{c}\text { Methoxyl substituents in phenolic units; } \\
\text { the cleavage of } \gamma \text {-carbon ending with hy- } \\
\text { droxyl group in the alkyl side chains }\end{array}$ & Terminal $-\mathrm{CH}_{2} \mathrm{OH}$ groups \\
\hline 44 & $\begin{array}{c}\mathrm{CO}_{2} \text { or } \\
\mathrm{CH}_{3} \mathrm{CHO}\end{array}$ & Carboxyl, carbonyl and ether groups & Decarboxylation reaction \\
\hline
\end{tabular}

